\title{
Synergetic coordination and catecholamine chemistry for catalytic generation of nitric oxide on vascular stents
}

\author{
Xiangyang Li ${ }^{1}$, Hua Qiu', Peng Gao', Ying Yang ${ }^{1}$, Zhilu Yang ${ }^{1}$ and Nan Huang ${ }^{1}$
}

\begin{abstract}
The unique advantages of nitric oxide (NO) in cardiovascular disease therapy have driven the development of methods to functionalize cardiovascular stents for local generation of NO. However, current NO-generating materials used for surface engineering stents have limitations such as a complex fabrication process, poor stent adhesion strength, and low control of NO release. Herein, we apply synergetic coordination and catecholamine surface chemistry to develop an adhesive NO-generating coating with a copper-catecholamine framework through a simple, one-step molecule/ion co-assembly process. The copper-catecholic-selenocystamine framework provides glutathione peroxidase (GPx)-like interfacial catalytic activity, which results in long-term, stable, adjustable NO release rates from the coating. The resulting desirable therapeutic dose and release kinetics of $\mathrm{NO}$ endow the vascular stent with the ability to simultaneously inhibit platelet activation and smooth muscle cell (SMC) proliferation, and enhances endothelial cell (EC) adhesion, proliferation, and migration in vitro. Vascular stent functionalized by the optimized copper-catecholic-selenocystamine coating significantly suppresses thrombosis, promotes re-endothelialization, and reduces intimal hyperplasia in vivo, and may be promising to address the clinical complications associated with restenosis and late stent thrombosis.
\end{abstract}

\section{Introduction}

Cardiovascular diseases (CVDs) continue to be the leading cause of death and disability all over the world ${ }^{1}$. Currently, intervention with cardiovascular stents is the primary means of CVD therapy due to its effectiveness in maintaining vascular patency ${ }^{2}$. However, inevitable vessel wall injury after stenting frequently complicates pathobiology processes associated with leukocyte accumulation, inflammation, smooth muscle cell migration, and proliferation, which ultimately lead to restenosis in addition to the risk of thrombus formation on the foreign surface ${ }^{3-5}$.

\footnotetext{
Correspondence: Zhilu Yang (zhiluyang1029@home.swjtu.edu.cn) or Nan Huang (huangnan1956@163.com)

'Key Laboratory of Advanced Technology for Materials of the Education Ministry, School of Materials Science and Engineering, Southwest Jiaotong University, 610031 Chengdu, China
}

Native endothelium consisting of a monolayer of endothelial cells is an important part of blood vessels and plays a critical role in maintaining homeostasis in the cardiovascular system. Nitric oxide (NO), a unique endogenous signaling molecule in vascular biology, is endogenously produced by the endothelial cells (ECs) through oxidation of L-arginine by nitric oxide synthase (NOS). Continuous release of NO by ECs is crucial for preventing thrombosis $^{6}$, suppressing smooth muscle cell migration and proliferation $^{7}$, inhibiting leukocyte activation ${ }^{8}$, and promoting healing of atherosclerotic lesions ${ }^{9}$. Atherosclerosis, the major reason for cardiovascular diseases, results in the absence of native endothelium and leads to a decrease in NO production. Hence, there is great interest in biomimetic surface modification of cardiovascular stents as delivery vehicles that locally release or generate

\section{(C) The Author(s) 2018, corrected publication 2021}

(c) (i) Open Access This article is licensed under a Creative Commons Attribution 4.0 International License, which permits use, sharing, adaptation, distribution and reproduction cc) in any medium or format, as long as you give appropriate credit to the original author(s) and the source, provide a link to the Creative Commons license, and indicate if changes were made. The images or other third party material in this article are included in the article's Creative Commons license, unless indicated otherwise in a credit line to the material. If material is not included in the article's Creative Commons license and your intended use is not permitted by statutory regulation or exceeds the permitted use, you will need to obtain permission directly from the copyright holder. To view a copy of this license, visit http://creativecommons.org/licenses/by/4.0/. 
NO to address clinical complications associated with thrombosis and restenosis ${ }^{10}$.

The promising application of NO in CVDs has promoted research on efficient generation of $\mathrm{NO}$ over the last two decades. Organoselenium moieties and $\mathrm{Cu}$ (II) ions, two of the most popular species with glutathione peroxidase (GPx)-like catalytic activity to decompose Snitrosothiols (RSNO) and known endogenous NO donors, have been used for the design of NO-generating materials $^{11,12}$. To date, the methods for creating NOgenerating materials mainly involve immobilization of organoselenium moieties on polymer matrixes or surfaces of biomaterials with functional groups and doping $\mathrm{Cu}^{\mathrm{II}}$ organic ligand complexes into polymer matrixes ${ }^{13,14}$. However, most existing methods for covalent linking or coating organoselenium species or $\mathrm{Cu}^{\mathrm{II}}$-organic ligand complexes on a material surface generally involve tedious multistep processes including pretreatment of the material to introduce the functional groups and complex immobilization or coating procedures. Furthermore, the amount of organoselenium species or $\mathrm{Cu}^{\mathrm{II}}$-organic ligand complexes bound to a material is limited by the density of the introduced functional groups on the surface. As a result, the number of catalytic complexes on a cardiovascular stent surface is difficult to accurately control, which leads to an undesirable dose of $\mathrm{NO}$ and uncontrollable physiological effects. There are technical challenges in controlling the adhesion strength of polymer coatings containing organoselenium species or $\mathrm{Cu}^{\mathrm{II}}$ organic ligand complexes on the stent surface.

Based on the above drawbacks of these strategies for an ideal NO-generating stent coating, herein, we report a one-step molecule/ion co-assembly method to form an adhesive NO-generating coating inspired by the synergetic coordination and catecholamine chemistry found in mussel byssus and adhesive plaque formation processes. In this study, we used 3,4-dihydroxy-L-phenylalanine (Dopa), a very important adhesive amino acid widely present in byssus and adhesive plaques secreted by mussels (Fig. 1a, b), to crosslink selenocystamine $(\mathrm{SeCA})$ and copper ions $\left(\mathrm{Cu}^{2+}\right)$ and fabricate an NO-generating coating, called $\mathrm{Cu}^{\mathrm{II}}-\mathrm{Dopa} / \mathrm{SeCA}$, and bind the coating to the stent surface. Dopa is well known for its specific chemical catechol structure that allows strong interactions with $\left[\mathrm{Fe}^{3+}\right]$ to form $\left[\mathrm{Fe}(\mathrm{dopa})_{3}\right]$ coordination complexes, which have been proposed to crosslink Mussel foot protein 1 (mfp$1)^{15}$ in the byssus (Fig. 1c). The formation of [ $\left.\mathrm{Fe}(\mathrm{dopa})_{3}\right]$ coordination complexes in byssus is crucial for mussels to strongly adhere to the rocks ${ }^{16}$. Inspired by the byssal cuticle, the coordination chemistry was used to fabricate flexible coatings ${ }^{17}$. Additionally, the coexistence of catechol (Dopa) and amine (lysine) groups in the Mytilus edulis foot protein 5 (Mefp-5) is regarded as crucial for achieving adhesion to virtually any bulk material surface
(Fig. 1d $)^{18}$. In particular, the oxygen of the catechol in an alkaline solution allows Dopa to chemically interact with the amine groups. The resulting catecholamine chemistry allows dopamine and the derivative of Dopa to easily and spontaneously form thin coatings via secondary reactions, creating a variety of functional adlayers and good adhesion to a wide spectrum of materials through oxidative selfpolymerization ${ }^{19}$. Although coordination chemistry and catecholamine chemistry have been widely investigated for designing functional materials, little attention has been paid to the combination of coordination and catecholamine chemistry, especially for establishing a catalytically active surface. In this study, the NO-generating coating of $\mathrm{Cu}^{\mathrm{II}}$-Dopa/SeCA inspired by synergetic coordination and catecholamine chemistry solves the aforementioned challenges. Through a simple one-step "dip-coating" of a cardiovascular stent in an aqueous mixed solution of Dopa, SeCA, and $\mathrm{CuCl}_{2} \cdot 2 \mathrm{H}_{2} \mathrm{O}$, an adhesive thin $\mathrm{Cu}^{\mathrm{II}}$ Dopa/SeCA film was easily coated on a $316 \mathrm{~L}$ stainless steel (SS, a widespread metal material used for cardiovascular stents) stent. This new method not only simplifies the fabrication process of NO-generating coatings, but also enables the cardiovascular stent to steadily and controllably generate $\mathrm{NO}$ in situ.

\section{Material and methods \\ Materials}

Dopa hydrochloride $\left(M_{\mathrm{w}}=189.64 \mathrm{Da}\right.$, CAS 335081-044), selenocystamine hydrochloride ( $\mathrm{SeCA})\left(M_{\mathrm{w}}=246.07\right.$ Da, CAS 3542-13-0), copper (II) chloride dihydrate $\left(\mathrm{CuCl}_{2} \cdot 2 \mathrm{H}_{2} \mathrm{O}, 99 \%\right)$, and (hydroxymethyl)aminomethane (Tris) $\left(M_{\mathrm{w}}=121.14 \mathrm{Da}\right.$, CAS 77-86-1) were purchased from Sigma Aldrich. Milli-Q water (18 M $\Omega$, Millipore) was used in all experiments.

\section{Preparation of Cu"-Dopa/SeCA coatings}

$\mathrm{The} \mathrm{Cu}^{\mathrm{II}}$-Dopa/SeCA coating was deposited on a mirror polished $316 \mathrm{~L}$ SS substrate ( $\Phi 10 \mathrm{~mm}), 316 \mathrm{~L}$ SS foil $(0.5$ $\mathrm{cm} \times 1 \mathrm{~cm}$ ), and $316 \mathrm{~L}$ SS stent through a one-step dipcoating method by immersing the samples into the reaction solution at room temperature for $24 \mathrm{~h}$. The reaction solution was formulated by dissolving Dopa $(0.25 \mathrm{mg} /$ $\mathrm{mL}$ ), SeCA $\left(0.1 \mathrm{mg} / \mathrm{mL}\right.$ ), and $\mathrm{CuCl}_{2} \cdot 2 \mathrm{H}_{2} \mathrm{O}$ (defined concentrations from 0 to $50 \mathrm{mg} / \mathrm{mL})$ in Tris buffer $(1.2 \mathrm{mg} /$ $\mathrm{mL}, \mathrm{pH}$ 8.5). Thereafter, all the samples were ultrasonically cleaned with distilled water and dried.

\section{Electron paramagnetic resonance (EPR)}

EPR measurements were carried out to investigate the influence of $\mathrm{Cu}^{\mathrm{II}}$-Dopa coordination on the formation of the $\mathrm{Cu}^{\mathrm{II}}$-Dopa/SeCA framework. EPR spectra were obtained using a Bruker A320 with a microwave bridge (receiver gain, $1 \times 10^{5}$; modulation amplitude, 2 Gauss; microwave power, $20 \mathrm{~mW}$; modulation frequency, $100 \mathrm{kHz}$ ). 


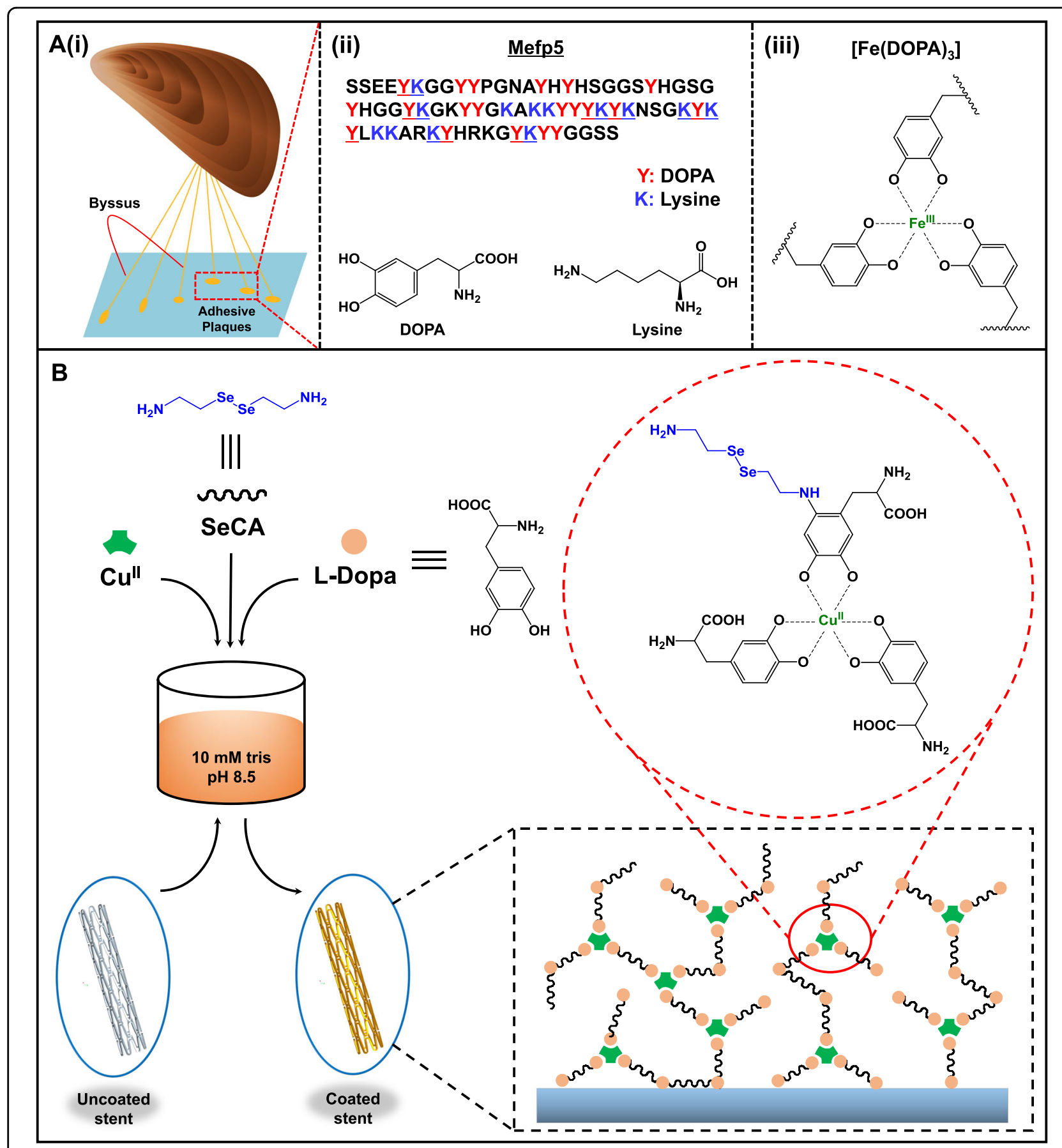

Fig. 1 Overall view of main reaction pathways involved in Cull-Dopa/SeCA formation. a Mussel byssus and adhesive plaques. (i) Schematic illustration of a mussel attached to a substrate surface with adhesive plaques interlinked by byssus; (ii) The amino acid sequence of Mytilus edulis foot protein 5 (Mefp-5) that is widely present in byssus and adhesive plaques secreted by mussels. The co-existence of two important compounds Dopa and lysine in Mefp-5 is crucial for achieving adhesion to a wide spectrum of materials; (iii) [Fe(dopa) ${ }_{3}$ coordination complexes proposed to crosslink mfp-1 in the byssus secreted by mussels. $\mathbf{b}$ Coordination and catecholamine synergetic surface chemistry for NO-generating coatings inspired by mussels. Dopa and $\mathrm{Cu}^{2+}$ with GPx-like catalytic activity to generate NO from RSNOs were chosen to form Cu"-Dopa coordination complexes inspired by $\left[\mathrm{Fe}(\mathrm{dopa})_{3}\right]$ coordination chemistry, and SeCA with a lysine-like crosslinking reaction was further used to link the Dopa-Cu" coordination complexes to form Cu"-Dopa/SeCA polymer-based catecholamine chemistry. Here, SeCA has also been shown to possess GPx-like catalytic activity 


\section{Matrix-assisted laser desorption/ionization mass spectrometry (MALDI MS)}

MALDI MS was used to analyze the chemical structure of the $\mathrm{Cu}^{\mathrm{II}}$-Dopa/SeCA framework. The detailed process has been reported elsewhere ${ }^{20}$.

\section{X-ray photoelectron spectroscopy (XPS)}

XPS (K-Alpha, Thermo Electron, USA) was performed to detect the surface chemical compositions of the sample. A monochromatic $\mathrm{Al} \mathrm{K} \alpha(1486.6 \mathrm{eV}) \mathrm{X}$-ray source was employed as an excitation source $(\mathrm{h} v=1486.6 \mathrm{eV})$, which was operated at $12 \mathrm{kV} \times 15 \mathrm{~mA}$ under a pressure of $3 \times 10^{-7} \mathrm{~Pa}$. The reference for charge correction was the graphitic carbon peak $(285 \mathrm{eV})$.

\section{Thickness measurement}

A spectroscopic ellipsometer (M-2000V, J.A. Woollam, USA) was used to measure the thickness of the coating. It was run in the Cauchy model, and $\Delta$ and $\Psi$ values were measured in the wavelength range of $370-1000 \mathrm{~nm}$.

\section{Scanning electron microscopy (SEM)}

SEM (Quanta 200, FEI, Holland) was used to observe the morphology of the $\mathrm{Cu}^{\mathrm{II}}$-Dopa/SeCA-coated $316 \mathrm{~L} \mathrm{SS}$ vascular stents $(1.65 \mathrm{~mm} \times 18 \mathrm{~mm})$, which was expanded from $1.65 \mathrm{~mm}$ to $3.0 \mathrm{~mm}$ (diameter) at a pressure of $8 \mathrm{~atm}$ by an angioplasty balloon.

\section{Catalytic release of NO}

A chemiluminescence $\mathrm{NO}$ analyzer (NOA) (Seivers 280i, Boulder, CO) was used to detect the real-time NO release. In detail, the $\mathrm{Cu}^{\mathrm{II}}$-Dopa/SeCA coating was deposited on $316 \mathrm{~L} \mathrm{SS}$ foil $(0.5 \mathrm{~cm} \times 1 \mathrm{~cm})$. After $5 \mathrm{~min}$ of baseline calibration of NO level, the sample was plunged into $5 \mathrm{~mL}$ of the detecting PBS solution composed of 10 $\mu \mathrm{M}$ NO donor of S-nitrosoglutathione (GSNO, an endogenous RSNO species) or S-nitro-socysteine (CysNO, an endogenous RSNO species) and $10 \mu \mathrm{M}$ glutathione (GSH, an endogenous reducing agent) at $37^{\circ} \mathrm{C}$ for approximately $40 \mathrm{~min}$. NO catalytic samples catalyze the decomposition of RSNO to generate NO, which was swept continuously by nitrogen gas $\left(\mathrm{N}_{2}\right)$ and transferred to the chemiluminescence detection chamber. In the detection chamber, NO reacts with ozone to produce $\mathrm{NO}_{2}{ }^{*}$ (the excited state of nitrogen dioxide). Then, $\mathrm{NO}_{2}{ }^{*}$ decays with a photon emission ( $\lambda$ between $600-875 \mathrm{~nm}$ ), which is measured by a photomultiplier tube (PMT), and the signal is proportional to the real-time concentration of NO.

\section{Platelet adhesion test and cyclic guanylate monophosphate (cGMP) analysis}

The fresh human venous blood used in this research was obtained from the Chengdu blood center station following ethics rules. All experiments were carried out within $12 \mathrm{~h}$ after the blood donation, and trisodium citrate (4\% wt) in a 9:1 volumetric ratio was used here as an anticoagulant.

Platelet rich plasma (PRP) was acquired by centrifugation (1500 r.p.m., $15 \mathrm{~min}$ ) of fresh human whole-blood. Afterwards, $350 \mu \mathrm{L}$ of PRP was dropped onto each sample and incubated at $37^{\circ} \mathrm{C}$ in damp air. The $\mathrm{NO}$ donor solution $(10 \mu \mathrm{M}$ GSNO and $10 \mu \mathrm{M}$ GSH) was also added to the PRP for comparison analysis. After $30 \mathrm{~min}$, PRP was removed and the samples were washed with saline solution, fixed with glutaraldehyde (2.5\%) overnight, and dehydrated and dealcoholized. Finally, the samples were inspected by SEM.

A human cGMP ELISA kit was used to detect the cGMP expression of platelets after being impacted with $\mathrm{NO}$ catalyzed by $\mathrm{Cu}^{\mathrm{II}}$-Dopa/SeCA. Similar to the platelet adhesion experiment, each sample was incubated in $1 \mathrm{~mL}$ of PRP with and without donor supplementation. After $30 \mathrm{~min}, 100 \mu \mathrm{L}$ of $10 \%$ Triton $\mathrm{X}$ was added to each well and treated with ultrasound. Afterwards, the suspensions were centrifuged at 2500 r.p.m. to isolate the supernatant for analysis.

\section{Human umbilical vein endothelial cell (HUVEC) and human} umbilical artery smooth muscle cell (HUASMC) isolation

HUVECs and HUASMCs were obtained from human umbilical vessels. The detailed cell culture processes have been reported elsewhere ${ }^{21}$.

\section{Cell attachment, proliferation, and cGMP analysis}

All the in vitro cell (HUVEC and HUASMC) experiments were set as two groups (one with NO donor $(10 \mu \mathrm{M}$ GSNO and $10 \mu \mathrm{M}$ GSH) in the cell media and another without donor in the cell media) to explore the influence of NO generation on cell growth behaviors.

In detail, primary HUVECs and HUASMCs were digested by trypsin $(0.25 \mathrm{wt} \%)$, seeded on samples with a density of $5 \times 10^{4}$ cells per $/ \mathrm{cm}^{2}$, and then placed in a cell incubator at $37^{\circ} \mathrm{C}$ in damp air with $5 \% \mathrm{CO}_{2}$. The $\mathrm{NO}$ donor solution was added to the cell media every $4 \mathrm{~h}$. After 2, 24, and $72 \mathrm{~h}$, the samples were sequentially washed with saline solution, fixed with glutaraldehyde (2.5\%), and stained with Rhodamine 123 . A cell counting kit-8 (CCK-8) was used to detect cell bioactivity after 24 and $72 \mathrm{~h}$ of culture.

A human cGMP ELISA kit was used to detect the cGMP expression of HUASMCs impacted with NO catalyzed by $\mathrm{Cu}^{\mathrm{II}}$-Dopa/SeCA. Similar to the adhesion experiment, HUASMCs were digested by trypsin $(0.25 \%$ wt) and then seeded on the samples with a density of $5 \times$ $10^{4}$ cells per $\mathrm{cm}^{2}$. Samples were immersed in a $1 \mathrm{~mL}$ cell suspension with and without NO donor $(10 \mu \mathrm{M}$ GSNO and $10 \mu \mathrm{M}$ GSH). After $2 \mathrm{~h}, 100 \mu \mathrm{L}$ of $10 \%$ Triton $\mathrm{X}$ was 
added to each cell well and treated with ultrasound. Afterwards, the cell suspensions were centrifuged at 2500 r.p.m. to isolate the supernatant for analysis.

\section{Co-culture of HUVECs and HUASMCs}

To mark the different cells, cell trackers with different colors were used to prelabel HUVECs (green chloromethyl fluorescein diacetate, CMFDA) and HUASMCs (orange chloromethyl trimethyl rhodamine, CMTMR) for $30 \mathrm{~min}$. Then, these two types of cells were digested by trypsin $(0.25 \% \mathrm{wt})$ and mixed at a ratio of $1: 1$ in DMEM/F12 medium with 10\% fetal bovine serum and a density of $5 \times 10^{4}$ cells per $\mathrm{cm}^{2}$. Finally, the mixed cell suspensions were added to the samples and cocultured for 2 and $24 \mathrm{~h}$ in a cell incubator at $37^{\circ} \mathrm{C}$ in damp air with $5 \% \mathrm{CO}_{2}$. The cells were observed and photographed using a Leica DMRX fluorescence microscope. The number of adherent cells was counted from at least 12 images by ImageJ.

\section{HUVEC and HUASMC migration assays}

The migration assays were performed to investigate the impact of NO generation on the HUVECs and HUASMCs. $\mathrm{Cu}^{\mathrm{II}}$-Dopa/SeCA was prepared on $316 \mathrm{~L}$ SS foil $(0.8 \mathrm{~cm} \times 2 \mathrm{~cm})$, and both the control and $\mathrm{Cu}^{\mathrm{II}}$-Dopa/ SeCA-coated foils were bent in the middle to an L-shape. Cells were digested and seeded on one flank of the Lshape with a density of $1 \times 10^{5}$ cells $/ \mathrm{cm}^{2}$. After $6 \mathrm{~h}$, all samples were turned over so that another flank of the Lshaped samples was immersed in the cell media and the adherent cells started to migrate. After $24 \mathrm{~h}$, the samples were washed with saline solution, fixed with glutaraldehyde (2.5\%), and stained with Rhodamine 123 . The migrated cells were observed and photographed using a Leica DMRX fluorescence microscope.

\section{Ex vivo thrombogenicity}

All animal handling and surgical procedures were performed in compliance with protocols approved by the Local Ethical Committee and Laboratory Animal Administration Rules of China following the ethical rules. Eight adult New Zealand white rabbits $(3.5-4 \mathrm{~kg})$ were used in this experiment. After injecting $30 \mathrm{mg} / \mathrm{mL}$ pentobarbital sodium through the ear vein, the rabbit left carotid artery and right external jugular vein were isolated and connected with tubes to form a blood circuit. The uncoated and $\mathrm{Cu}^{\mathrm{II}}$-Dopa/SeCA-coated $316 \mathrm{~L}$ SS foils $(0.8$ $\mathrm{mm} \times 1 \mathrm{~mm}$ ) were rolled and assembled into tubes. The circuit was stopped after $2 \mathrm{~h}$. The clot in the tube around the specimen was collected, photographed, and weighed. The samples were removed, washed with saline solution, fixed with glutaraldehyde (2.5\%) overnight, and dehydrated and dealcoholized. Finally, all the samples were inspected by SEM.

\section{In vivo stent implantation}

All processes were performed in agreement with the China Council on Animal Care and Southwest Jiaotong University animal use protocol, in accordance with the ethical rules for experiments on animals. Eight adult New Zealand white rabbits $(3.5-4 \mathrm{~kg})$ and sixteen stents were used in this experiment. All rabbits underwent ballooninduced arterial wall injury and were fed a high-fat diet for 2 weeks. After general anesthesia and systemic anticoagulation, the rabbit iliac arteries were isolated, and the uncoated and $\mathrm{Cu}^{\mathrm{II}}$-Dopa/SeCA-coated 316 L SS stents were implanted into the left and right iliac arteries, respectively. All animals were fed aspirin for 1 week as postoperative anticoagulation therapy. After 1 and 3 months, the stents and the surrounding vessels were collected and fixed with $10 \%$ formaldehyde for 2-3 days. Half of the stents were snipped lengthwise, dehydrated, dealcoholized, and observed by SEM. The other half of the stents were embedded in paraffin and serially cut for further histologic examination.

\section{Results and discussion}

\section{Copper-catecholamine framework characterization}

To verify that the formation mechanism of the $\mathrm{Cu}^{\mathrm{II}}$ Dopa/SeCA framework was based on an ion/molecule coassembly process, electron paramagnetic resonance and matrix-assisted laser desorption ionization mass spectrometry were performed on the product harvested from a reaction solution of Dopa $(0.25 \mathrm{mg} / \mathrm{mL}), \mathrm{CuCl}_{2} \cdot 2 \mathrm{H}_{2} \mathrm{O}$ $(0.025 \mathrm{mg} / \mathrm{mL})$, and SeCA $(0.1 \mathrm{mg} / \mathrm{mL})$ dissolved in 10 $\mathrm{mM}$ Tris buffer (pH 8.5) after $12 \mathrm{~h}$. First, to demonstrate the contribution of the coordination reaction between Dopa and $\mathrm{Cu}^{2+}$ to the $\mathrm{Cu}^{\mathrm{II}}$-Dopa/SeCA framework, an EPR analysis of the reaction products from Dopa and SeCA with and without the addition of $\mathrm{CuCl}_{2}$ was first performed (Fig. 2a). For the collected product of Dopa/ $\mathrm{SeCA}$ without the addition of $\mathrm{CuCl}_{2}$, only a radical signal attributed to the oxidation of Dopa was observed (3530 $\mathrm{mT})^{22}$. In the case of the spectrum of $\mathrm{Cu}^{\mathrm{II}}-\mathrm{Dopa} / \mathrm{SeCA}$, significant signals of $\mathrm{Cu}^{\mathrm{II}}$-Dopa coordination complexes were detected $(3490-3430 \mathrm{mT})$, indicating the ion assembly contribution of $\mathrm{Cu}^{2+}$ and Dopa to the formation of the $\mathrm{Cu}^{\mathrm{II}}$-Dopa/SeCA framework. To more clearly understand the formation mechanism of the $\mathrm{Cu}^{\mathrm{II}}$-Dopa/ SeCA framework, MALDI MS measurements were carried out. The peak of the $[\mathrm{M}+\mathrm{H}]^{+}$ion at $893.5 \mathrm{~m} / \mathrm{z}$ is clearly present during polymerization (Fig. $2 \mathrm{~b}$ ), indicating the formation of the $\mathrm{Cu}^{\mathrm{II}}$-Dopa/SeCA framework via an ion/molecular coassembly process. Additionally, the detected peaks of $[\mathrm{M}+\mathrm{H}]^{+}$ions at 444, 665, 686, and 832 $\mathrm{m} / \mathrm{z}$ revealed the chemistry of Schiff-base formation and Michael addition between the amine and catecholic groups, as well as physical self-assembly between amine and carboxyl groups (Figure S1). 

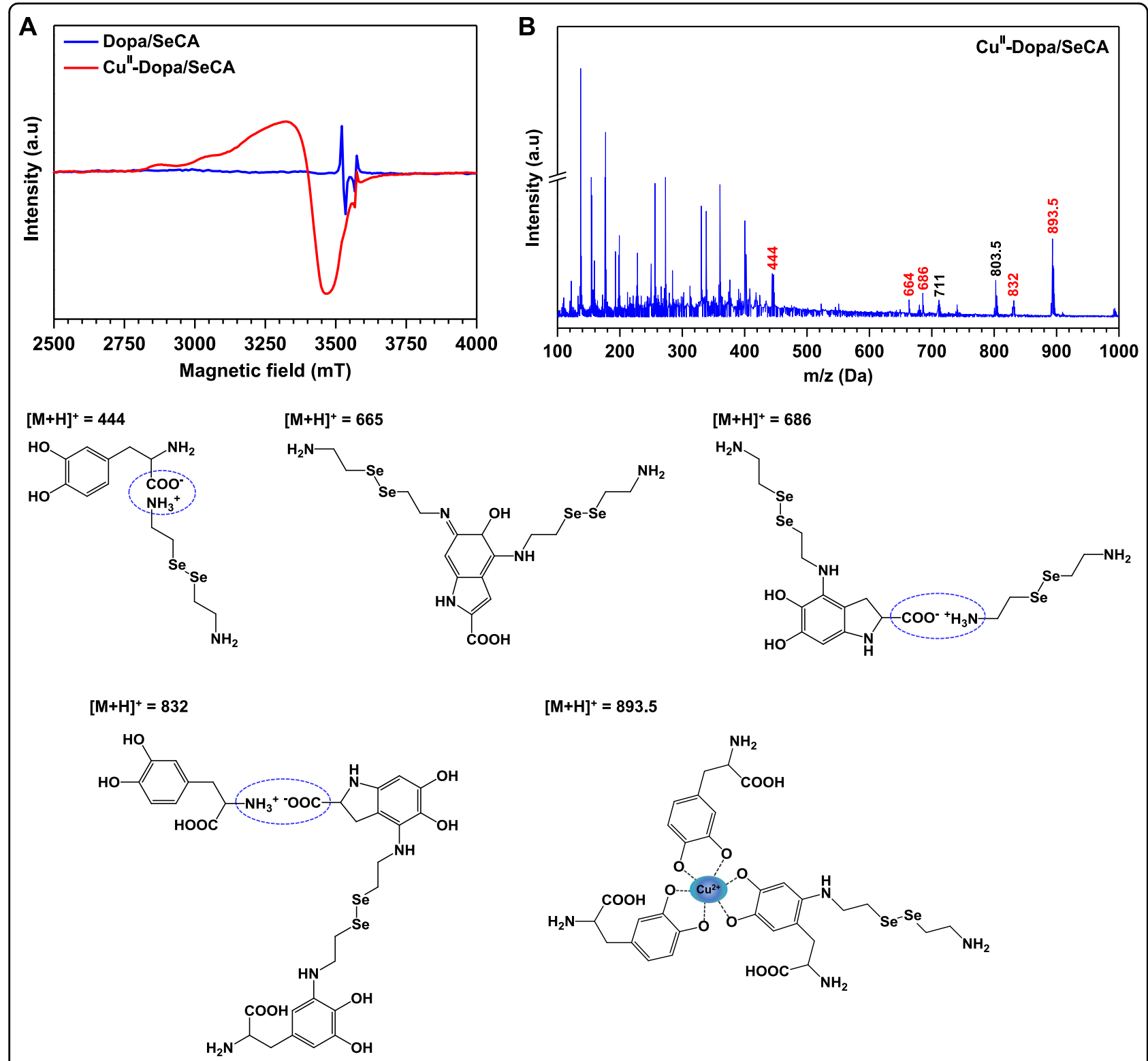

$[\mathrm{M}+\mathrm{H}]^{+}=\mathbf{8 9 3 . 5}$

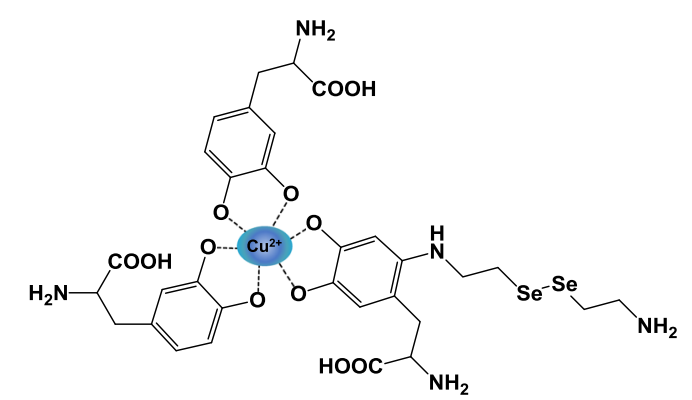

Fig. 2 EPR spectra and MALDI MS analysis of Cu"-Dopa/SeCA. a EPR spectra revealed the presence of the Cu"-Dopa signal at 3490-3430 mT, indicating the formation of Cu"-Dopa coordination complexes. b MALDI MS analysis of Cu"-Dopa/SeCA revealed the reaction mechanism of ion/ molecular assembly among Dopa, $\mathrm{Cu}^{2+}$, and SeCA

\section{Copper-catecholamine framework for NO-generating coatings}

To confirm the feasibility of coordination and catecholamine synergetic surface chemistry for establishing an NO-generating coating, a mixture solution of catechol, Dopa $(0.25 \mathrm{mg} / \mathrm{mL})$, SeCA $(0.1 \mathrm{mg} / \mathrm{mL})$, and $\mathrm{CuCl}_{2} \cdot 2 \mathrm{H}_{2} \mathrm{O}$ with feed concentrations ranging from 3.125 to $50 \mu \mathrm{g} / \mathrm{mL}$ was employed on a $316 \mathrm{~L}$ SS substrate, which is a widespread metal material for vascular stents. After immersion for $12 \mathrm{~h}$, the SS substrates showed a polydopamine-like dark-brown color (Fig. 3a). Ellipsometry analysis revealed that the thickness of $\mathrm{Cu}^{\mathrm{II}}$-Dopa/SeCA coatings prepared with a feed concentration of $\mathrm{CuCl}_{2} \cdot 2 \mathrm{H}_{2} \mathrm{O}$ from 0 to $50 \mu \mathrm{g} /$ $\mathrm{mL}$ ranged from 14 to $23 \mathrm{~nm}$ (Fig. 3b). Analysis by X-ray photoelectron spectroscopy revealed the absence of signals specific to the SS substrates (Fig. 3c, Figure S2), indicating complete coverage of the substrates by the coatings. With different feed concentrations of $\mathrm{CuCl}_{2}$, coatings with a wide range of atomic compositions of copper and selenium were obtained (Fig. 3d, Table S1), confirming the potential controllability of the $\mathrm{Cu}^{\mathrm{II}}$-Dopa/ SeCA surface chemistry at the molecular level for vascular stents. Next, the catalytic ability of the $\mathrm{Cu}^{\mathrm{II}}-\mathrm{Dopa} / \mathrm{SeCA}$ coatings for $\mathrm{NO}$ formation was investigated. 

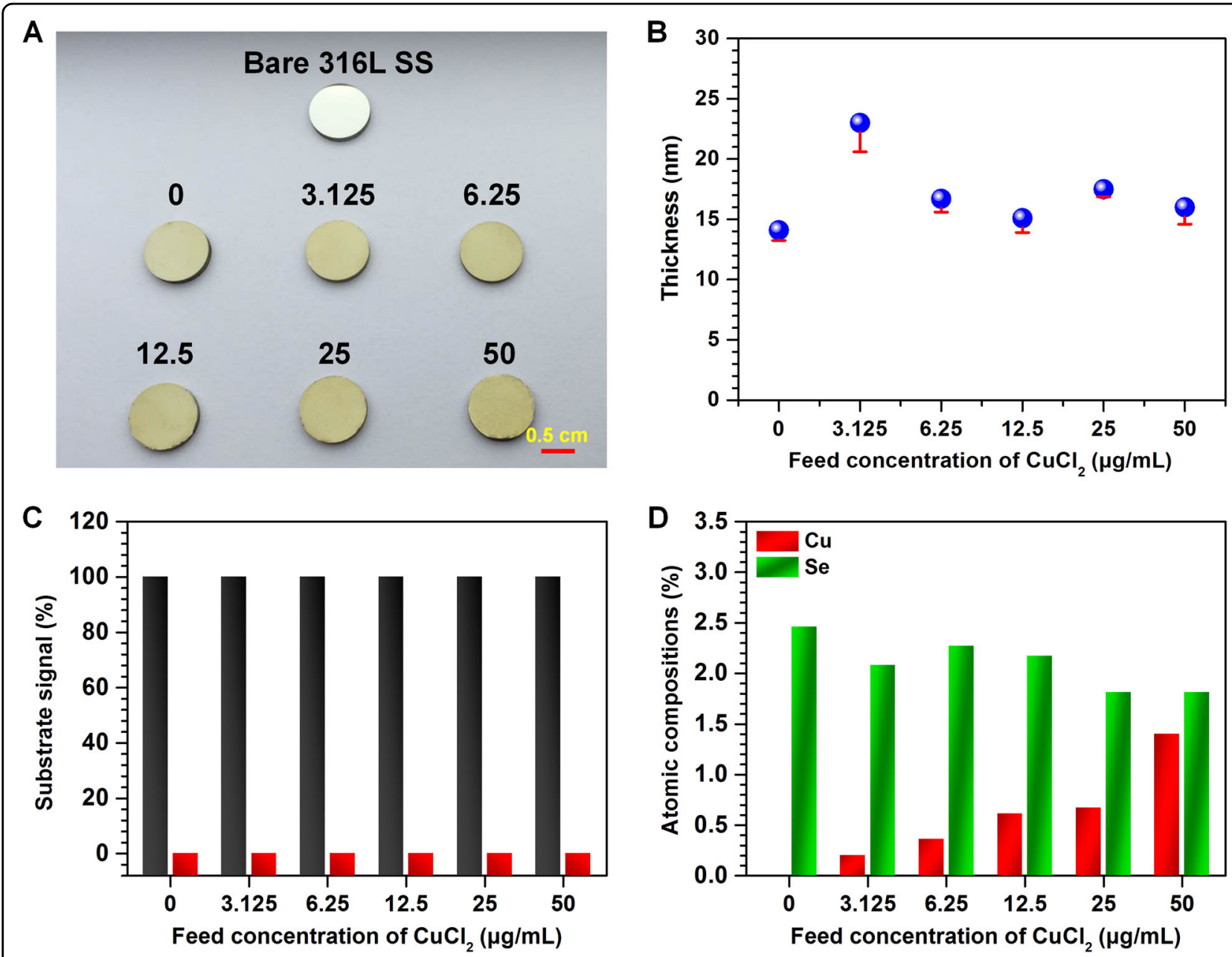

Fig. 3 a Control 316 L SS substrate before and after modification by Cu"-Dopa/SeCA coatings fabricated using different feed concentrations of CuCl 2 ranging from 0 to $50 \mathrm{\mu g} / \mathrm{mL}$. b The thickness of the Cu"-Dopa/SeCA coatings. c $316 \mathrm{~L} \mathrm{SS}$ substrate signal (Fe 2p) measured by XPS before (black) and after (red) modification by a Cu"-Dopa/SeCA coating. A value of 100\% indicates the absence of a measured coating. $\mathbf{d}$ The atomic compositions of Cu and $\mathrm{Se}$ in the Cu"-Dopa/SeCA coatings

Here, a real-time chemiluminescent assay ${ }^{23}$ was used to evaluate the NO-release behavior of the $\mathrm{Cu}^{\mathrm{II}}$-Dopa/SeCA coatings on a $316 \mathrm{~L}$ SS substrate. Release rates of NO induced by the $\mathrm{Cu}^{\mathrm{II}}$-Dopa/SeCA coatings with different feed concentrations of $\mathrm{CuCl}_{2} \cdot 2 \mathrm{H}_{2} \mathrm{O}$ were measured in PBS (pH 7.4) supplemented with $10 \mu \mathrm{M}$ S-nitrosoglutathione and $10 \mu \mathrm{M}$ glutathione. As shown in Fig. 4a, real-time monitoring of $\mathrm{NO}$ generation from the $\mathrm{Cu}^{\mathrm{II}}-\mathrm{Dopa} / \mathrm{SeCA}$ coatings revealed a constant $\mathrm{NO}$ release after the samples were immersed in PBS for several minutes, indicating that the coordination and catecholamine synergetic surface chemistry were successful for $\mathrm{Cu}^{\mathrm{II}}$ chelation and SeCA crosslinking. Additionally, we found that the release rate of $\mathrm{NO}$ induced by the $\mathrm{Cu}^{\mathrm{II}}$-Dopa/SeCA coatings was highly dependent on the feed concentration of $\mathrm{CuCl}_{2}$; i.e., for higher concentrations of $\mathrm{CuCl}_{2}$, higher NO-release rates were obtained (Fig. 4b). More importantly, the $\mathrm{Cu}^{\mathrm{II}}$ -
Dopa/SeCA coatings exhibited good long-term NO catalytic activity. After continuous exposure to the NO donor in PBS for 1 month, the $\mathrm{Cu}^{\mathrm{II}}$-Dopa/SeCA coating retained $44 \%$ of the NO-release rate of a native $\mathrm{Cu}^{\mathrm{II}}$ Dopa/SeCA coating (Figure S3), which is ascribed to good retention of the $\mathrm{Cu}$ content in the coating (Figure S4).

As many endogenous RSNO species (e.g., Snitrosoglutathione (GSNO), S-nitrosoalbumin (AlbSNO), and S-nitrosocysteine (CysNO)) coexist in fresh blood, we also evaluated the catalytic activity of the $\mathrm{Cu}^{\mathrm{II}}$-Dopa/ SeCA coating using other RSNO species of CysNO. The chemiluminescent results revealed that an efficient NOrelease rate of $5.83 \pm 0.62 \times 10^{-10} \mathrm{~mol} \times \mathrm{cm}^{-2} \times \mathrm{min}^{-1}$ was obtained using $10 \mu \mathrm{M}$ CysNO (Figure S5A), indicating the effective catalytic activity of our coating using different RSNO species. Moreover, the actual levels of endogenous RSNO in the blood were lower than that used 

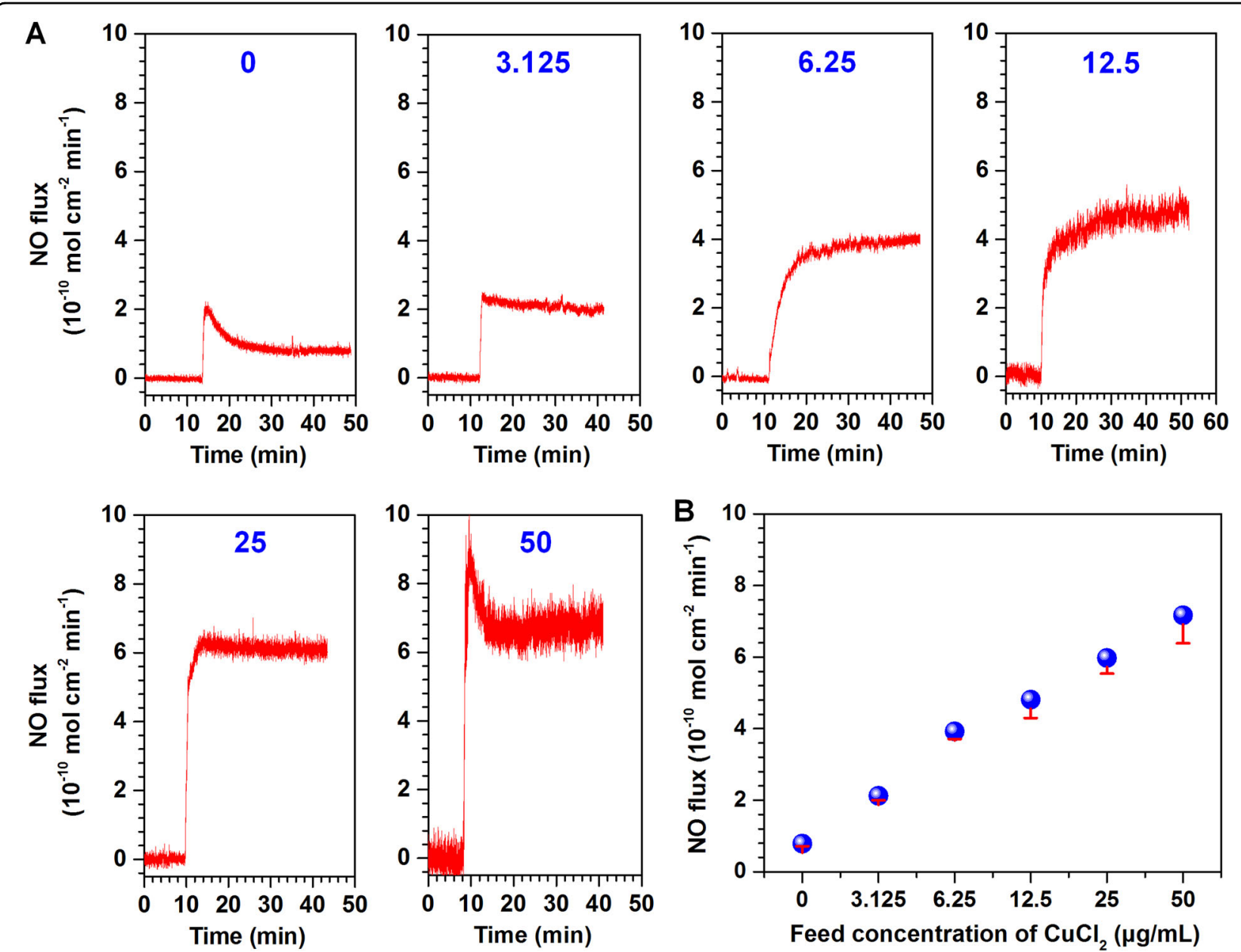

Fig. 4 (Red) Retention of $\mathrm{Cu}$ content and (Blue) atomic composition of $\mathrm{Cu}$ of the Cull-Dopa/SeCA coating (when [Dopa] and [SeCA] were kept constant at $0.25 \mathrm{mg} / \mathrm{mL}$ and $0.1 \mathrm{mg} / \mathrm{mL}$ respectively, CulIDopa/SeCA coating was obtained using a [CuCl2] of $12.5 \mu \mathrm{g} / \mathrm{mL}$ ) after continuous exposure to PBS (pH 7.4) containing NO donor (10 $\mu \mathrm{M}$ GSNO and $10 \mu \mathrm{M} \mathrm{GSH}$ ). The NO donor solution was replaced every $12 \mathrm{~h}$. a Catalytic NO generation patterns and (b) statistical results of the release rates of NO induced by Cu"-Dopa/SeCA coatings prepared with different feed concentrations of $\mathrm{CuCl}_{2} \cdot 2 \mathrm{H}_{2} \mathrm{O}$ in PBS (pH 7.4) containing NO donor (10 $\mu \mathrm{M}$ GSNO and $\left.10 \mu \mathrm{M} \mathrm{GSH}\right)$

for NO generation in this study. Therefore, we further evaluated the NO-release behavior of the $\mathrm{Cu}^{\mathrm{II}}$-Dopa/ SeCA coating using lower levels of GSNO (e.g., $1 \mu \mathrm{M}$ and $0.1 \mu \mathrm{M})$. It was found that the decreased GSNO levels resulted in a visible decrease in $\mathrm{NO}$ generation from the $\mathrm{Cu}^{\mathrm{II}}$-Dopa/SeCA coating. The NO-release rates were reduced to $2.32 \pm 0.37$ and $0.56 \pm 0.11 \times 10^{-10} \mathrm{~mol} \times$ $\mathrm{cm}^{-2} \times \min ^{-1}$ when $1 \mu \mathrm{M}$ and $0.1 \mu \mathrm{M}$ GSNO, respectively, were used (Figure S5B, C), which was lower than that generated by $\mathrm{Cu}^{\mathrm{II}}$-Dopa/SeCA using $10 \mu \mathrm{M}$ GSNO $\left(4.81 \pm 0.52 \times 10^{-10} \mathrm{~mol} \times \mathrm{cm}^{-2} \times \mathrm{min}^{-1}\right)$. It is noteworthy to mention that patients with endothelial dysfunction produce less NO from the endothelial cell layer lining all blood vessels, and hence, such patients will also likely have lower levels of RSNOs in their blood, which potentially results in a large decrease in the effectiveness of the $\mathrm{Cu}^{\mathrm{II}}$-Dopa/SeCA-coated stents. Therefore, the proposed $\mathrm{Cu}^{\mathrm{II}}$-Dopa/SeCA stent coating may not work in every case.

Vascular stents undergo severe deformation during mounting on an angioplasty balloon and expanding when they are deployed. A coating must have sufficient adaptability to resist the deformation behavior of the stent. Herein, a stent analysis was performed as an example to evaluate the mechanical behavior of the $\mathrm{Cu}^{\mathrm{II}}$-Dopa/SeCA coating. First, a $316 \mathrm{~L}$ SS cardiovascular stent with a size of $1.65 \mathrm{~mm} \times 18 \mathrm{~mm}$ was coated with $\mathrm{Cu}^{\mathrm{II}}-\mathrm{Dopa} / \mathrm{SeCA}$, fabricated using $12.5 \mu \mathrm{g} / \mathrm{mL}$ initial $\mathrm{CuCl}_{2} \cdot 2 \mathrm{H}_{2} \mathrm{O}$, and mounted onto an angioplasty balloon using a stent crimper. Then, the balloon was dilated to $3 \mathrm{~mm}$ (diameter) at a pressure of $9 \mathrm{~atm}$ for $1 \mathrm{~min}$. After that, the surface morphology of the post-expansion stent was observed by field emission SEM to evaluate the mechanical properties of the Dopa/SeCA coating, as well as the 


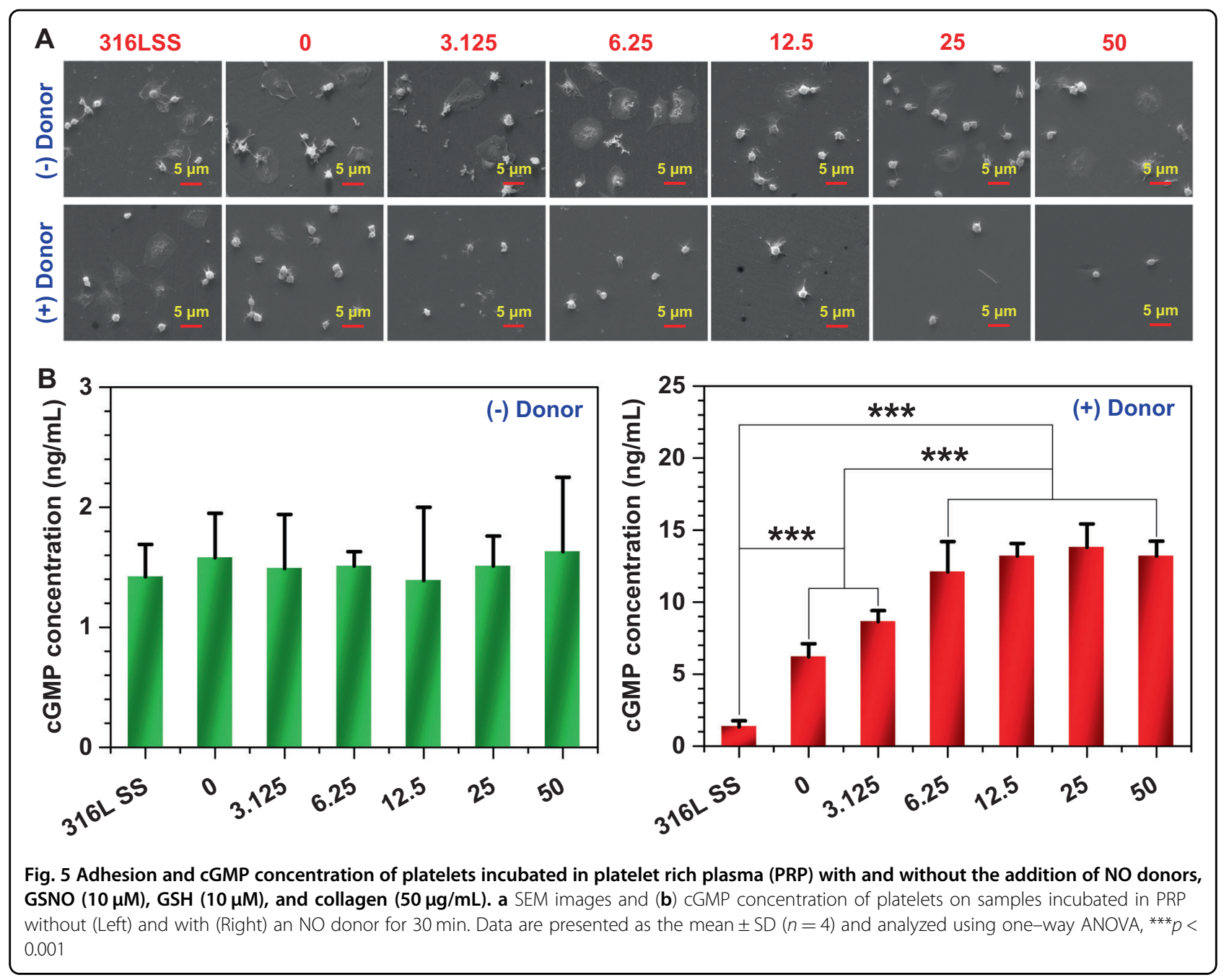

adhesion strength to stent. The SEM images clearly revealed that the SeCA/Dopa coating remained intact without destruction or peeling from the struts (Figure S6), indicating that Dopa/SeCA coating is sufficiently flexible to follow the deformation of the $316 \mathrm{~L}$ SS stent. Taken together, these results indicate that this one-step molecule/ion coassembly method inspired by coordination and catecholamine synergetic surface chemistry clearly outcompetes existing methods for NO-generating coatings.

\section{In vitro evaluation of platelet adhesion and vascular cell growth behavior}

The aforementioned properties of $\mathrm{Cu}^{\mathrm{II}}$-Dopa/SeCA coatings provide feasibility for further biological applications. NO is widely used to improve the anticoagulant activity and antirestenosis of blood-contacting devices such as tubing ${ }^{24,25}$, vascular grafts ${ }^{26-28}$, and cardiovascular stents due to its inhibition of platelet activation and SMC proliferation via the NO-cGMP signaling pathway ${ }^{29}$. Thus, we first investigated the biological effects of our
NO-generating coatings on platelets and SMCs. Here, for the in vitro tests of platelet adhesion and cell growth behaviors, NO donors GSNO and GSH were supplemented in platelet rich plasma and cell media to simulate the in vivo environment in the cardiovascular system. The results of platelet adhesion revealed that the uncoated and $\mathrm{Cu}^{\mathrm{II}}$-Dopa/SeCA-coated $316 \mathrm{~L}$ SS all caused severe platelet activation in the control group without an NO donor, whereas significant inhibitory effects on platelet adhesion and activation were found for the $\mathrm{Cu}^{\mathrm{II}}$-Dopa/ SeCA-coated 316 L SS after supplementation with an NO donor (Fig. 5a). Moreover, the inhibitory effects were enhanced with an increase in the feed concentration of $\mathrm{CuCl}_{2} \cdot \mathrm{H}_{2} \mathrm{O}$ during the preparation of the $\mathrm{Cu}^{\mathrm{II}}$-Dopa/ SeCA coatings due to the higher cGMP synthesis (Fig. 5b). Next, the effects of the $\mathrm{Cu}^{\mathrm{II}}$-Dopa/SeCA coatings on cell growth behavior were investigated. As expected, the $\mathrm{Cu}^{\mathrm{II}}$ Dopa/SeCA coating also showed a remarkable inhibitory effect on HUASMC adhesion by simulating cGMP synthesis in the group with an NO donor (Fig. 6a). 


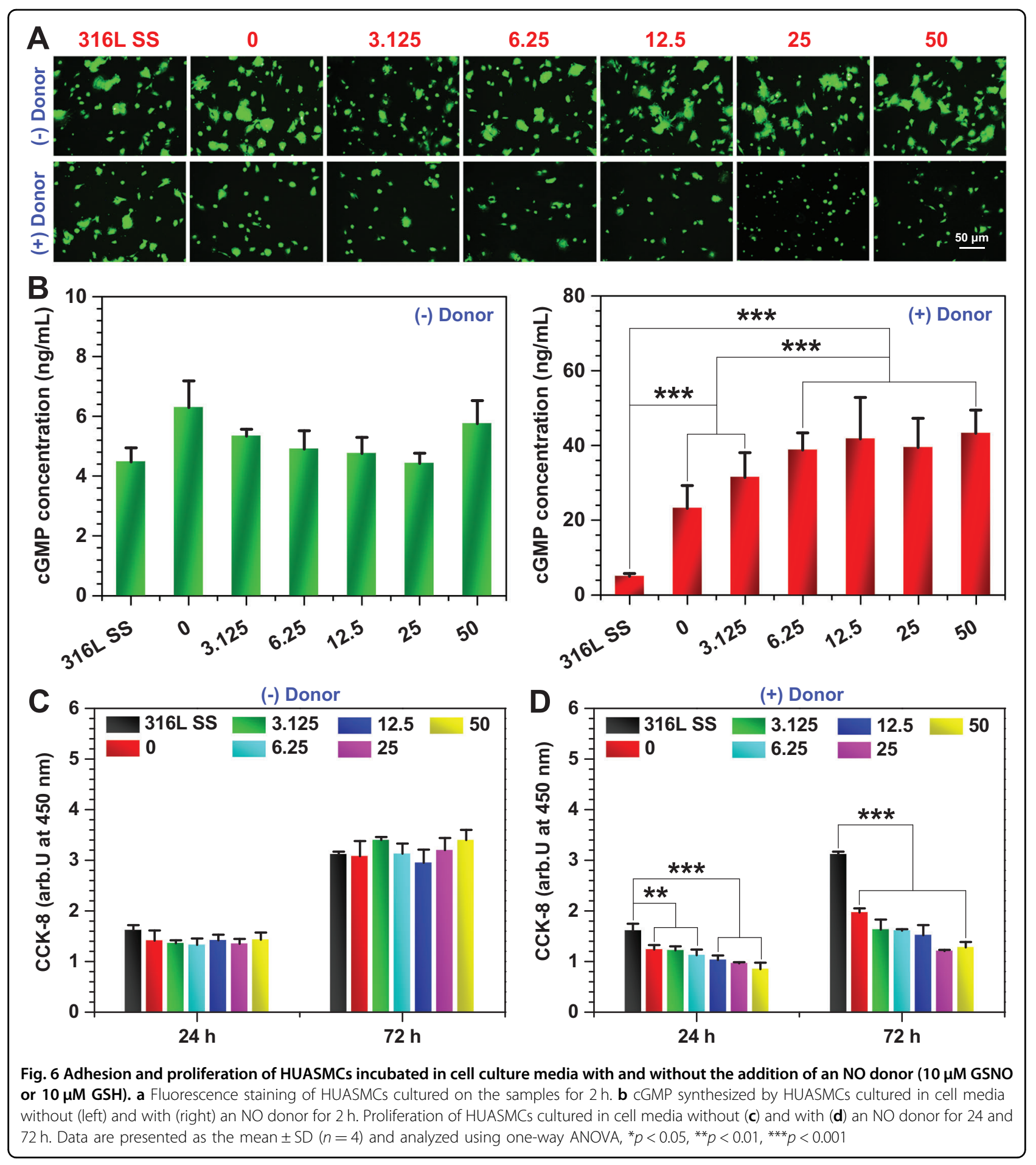

Continuous production of $\mathrm{NO}$ also significantly suppressed HUASMC proliferation (Fig. 6b, Figure S7). Despite the enhanced inhibitory effects on platelets and SMCs in the case of a higher NO dose, an excessive dose of NO might be harmful for re-endothelialization in vivo due to the possibility of peroxynitrite formation ${ }^{30}$. Regeneration of the endothelial layer is a key factor in the success of stent implantation. Thus, the effect of the $\mathrm{Cu}^{\mathrm{II}}$ Dopa/SeCA coatings on EC growth behavior was investigated. We found that if the initial concentration of $\mathrm{CuCl}_{2} \cdot 2 \mathrm{H}_{2} \mathrm{O}$ for the coating on the $316 \mathrm{~L}$ SS substrate exceeded $12.5 \mu \mathrm{g} / \mathrm{mL}$, the resultant $\mathrm{Cu}^{\mathrm{II}}-\mathrm{Dopa} / \mathrm{SeCA}$ coating led to a slight inhibition of human umbilical vein endothelial cell adhesion (Fig. 7a, b) and proliferation 


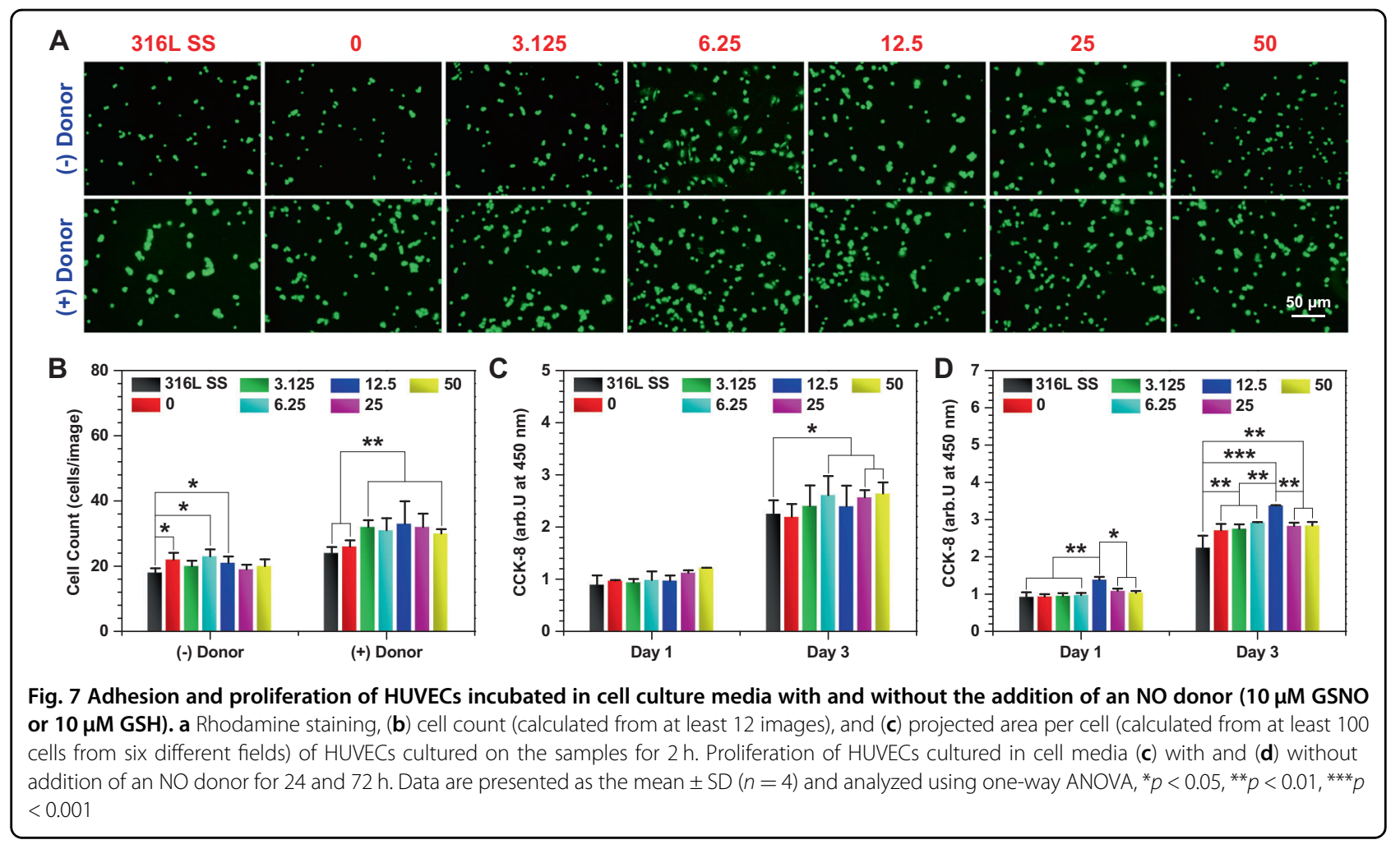

(Fig. 7c, $d$ and Figure S8). Based on this observation, the $\mathrm{Cu}^{\mathrm{II}}$-Dopa $/ \mathrm{SeCA}$ coatings prepared using $12.5 \mu \mathrm{g} / \mathrm{mL}$ of $\mathrm{CuCl}_{2} \cdot 2 \mathrm{H}_{2} \mathrm{O}$ were optimized and used as the experimental group for the following biological evaluations.

In recent years, a number of researchers ${ }^{31,32}$ including our group ${ }^{10,33,34}$ have demonstrated that the outperformance of ECs over SMCs endowed by vascular stents is crucial for regeneration of a healthy endothelia layer and implantation success. In this work, the competitive ability of the ECs and SMCs was also tested by coculture of HUVECs and HUASMCs that were labeled with different cell tracker dyes. Competitive cell adhesion and proliferation revealed that the $\mathrm{Cu}^{\mathrm{II}}$-Dopa/SeCA coating selectively enhanced HUVEC growth, while suppressing HUASMC adhesion and proliferation on coated $316 \mathrm{~L} \mathrm{SS}$, compared with that of the uncoated control, as evidenced by the significant increase in the ratio of HUVECs to HUASMCs in the groups with an NO donor (Figure S9). Additionally, it was found that the $\mathrm{Cu}^{\mathrm{II}}$-Dopa/ SeCA coating also inhibited HUASMC migration (Figure S10) and enhanced HUVEC migration (Figure S11) in the case of addition of an NO donor.

\section{Ex vivo thrombogenicity}

To test the antithrombogenic properties of the $\mathrm{Cu}^{\mathrm{II}}$ Dopa/SeCA coatings, an ex vivo perfusion experiment was carried out. The $316 \mathrm{~L}$ SS foils before and after coating with $\mathrm{Cu}^{\mathrm{II}}$-Dopa/SeCA were placed on the luminal wall of polyvinyl chloride cardiopulmonary perfusion tubes and assembled in a New Zealand white rabbit arteriovenous shunt (Fig. 8a). After $2 \mathrm{~h}$ of ex vivo circulation in the arteriovenous shunts supplemented with $\mathrm{NO}$ donor, the conditions of thrombosis formation, occlusion induced by thrombosis, and blood flow rates in the coated and uncoated groups were evaluated. As shown in Fig. 8b, c, the uncoated 316 L SS foils induced severe thrombosis and resulted in $85.6 \pm 10.5 \%$ occlusion (calculated by measuring the cross-section diameter of the circulating tube) (Fig. 8d), whereas no visible thrombosis and no detectable occlusion were observed in the group of the coated foils. Scanning electron microscopy also confirmed that the coated 316 L SS impressively suppressed platelet activation and fibrin formation (Fig. 8e). On the uncoated $316 \mathrm{~L}$ SS, severe thrombi consisting of fibrin, red blood cells, and activated platelets were observed. In contrast, only a small number of platelets with dendritic or even round states were found on the coated 316 L SS. Quantitative analysis of the thrombus weight revealed that the total weight of thrombus harvested from coated $316 \mathrm{~L} \mathrm{SS}$ foil was $6.6 \pm 0.4 \mathrm{mg}$, which was approximately $8.1 \%$ of the weight of the thrombus formed on the uncoated 316 L SS foil (Fig. 8f). Furthermore, blood flow rates in the circuit after $2 \mathrm{~h}$ of circulation were tested. Compared with the remarkable reduction in the blood flow rate in the uncoated group $(22.5 \pm 11.3 \%$ of the initial rate), the coated group still retained a high flow rate of $87.3 \pm 6.8 \%$ 
A
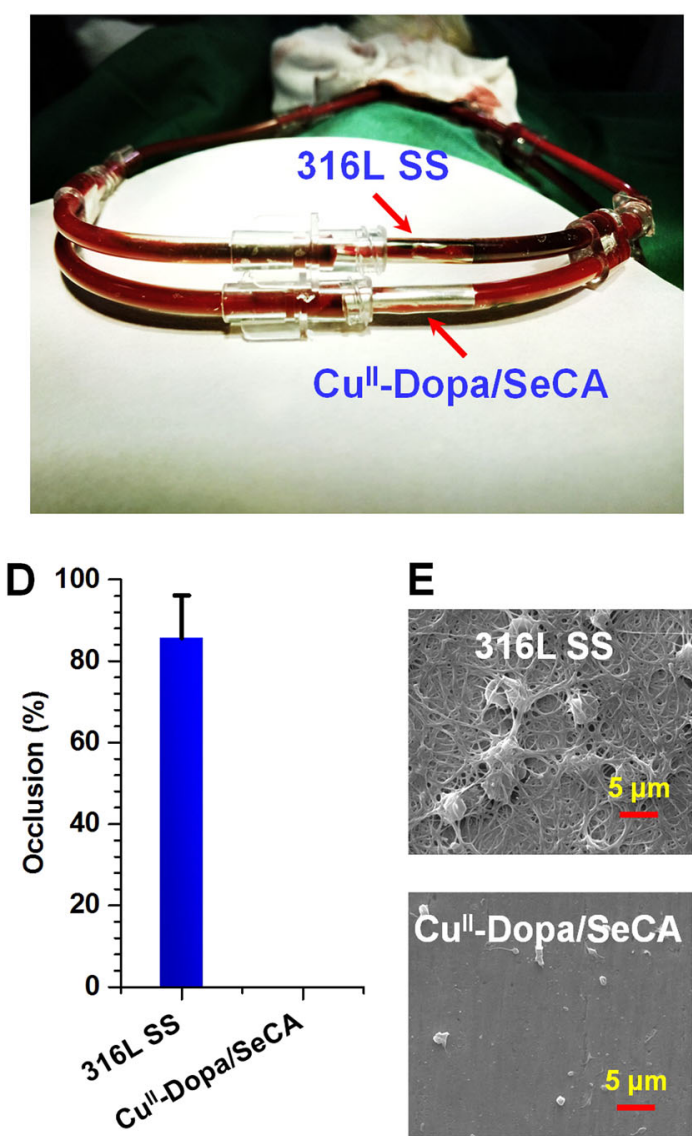

B

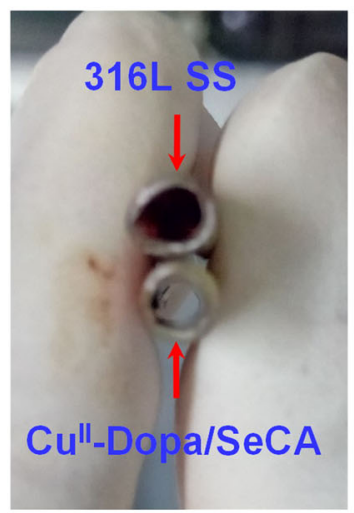

E
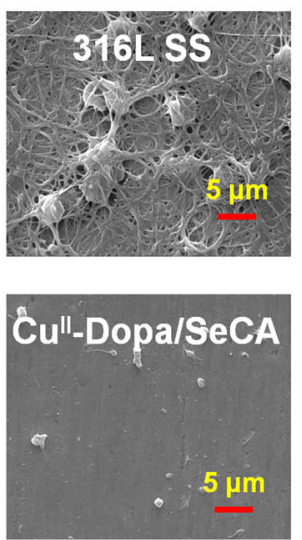
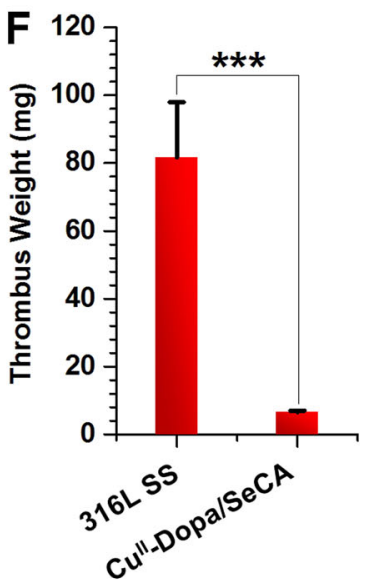

C
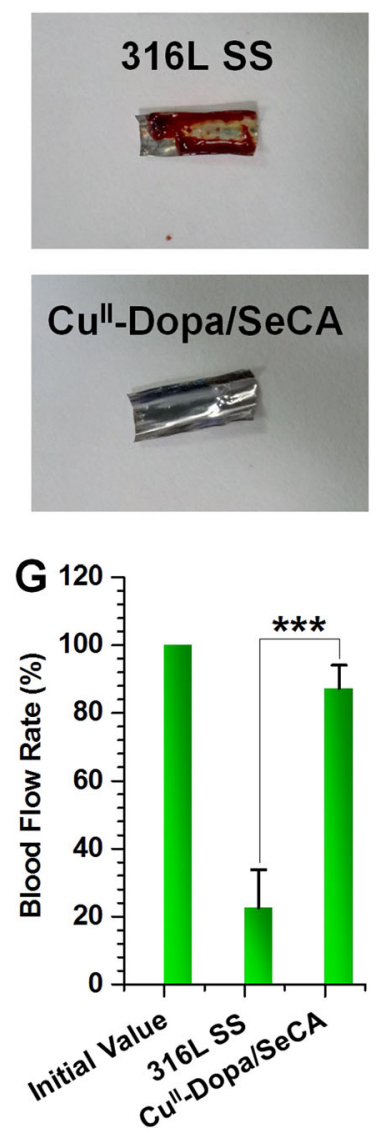

Fig. 8 Thrombogenicity of Cu"-Dopa/SeCA-coated $316 \mathrm{~L} \mathrm{SS}$ foils in a New Zealand white rabbit arteriovenous shunt model. a Image of the ex vivo circulation thrombogenicity of rabbits. b Cross-sectional photographs of tubing containing $316 \mathrm{~L}$ SS foils before and after modification by a Cull-Dopa/SeCA coating exposed for $2 \mathrm{~h}$ to blood flow in a rapid arteriovenous shunt model without heparin. $\mathbf{c}$ Photograph thrombus formed on $316 \mathrm{~L}$ SS foils before and after Cu"-Dopa/SeCA modification. $\mathbf{d}$ Percent occlusion of the cross-section reveals a significant reduction in occlusion after modification by Cu"-Dopa/SeCA. e SEM shows a significant reduction in the activation of platelets and fibrinogen on the Cu"-Dopa/SeCA-coated 316 L SS surface, compared to that of the control 316 L SS surface. f Thrombus weight is remarkably reduced in the Cu"-Dopa/SeCA-Coated 316 L SS circuit. g Cu"-Dopa/SeCA-coated 316 L SS circuit shows obvious improvement in blood flow rate at the end of ex vivo circulation experiments, compared to the control $316 \mathrm{~L} \mathrm{SS}$ circuit. Data are presented as the mean \pm SD of ex vivo circulation experiments and analyzed using one-way ANOVA, ${ }^{* * *} p<0.001$

(Fig. 8g). Taken together, these ex vivo results demonstrate that the $\mathrm{Cu}^{\mathrm{II}}$-Dopa/SeCA coating inspired by coordination and catecholamine synergetic surface chemistry provides an efficient strategy for surface engineering of vascular stents with antithrombogenic properties.

\section{In vivo cardiovascular stent implantation}

To demonstrate the feasibility of our developed $\mathrm{Cu}^{\mathrm{II}}$ Dopa/SeCA coating to address the issues of vascular stents associated with restenosis and LST, in vivo stent implantation into iliac arteries of New Zealand white rabbits was further carried out. After 1 and 3 months of implantation, the conditions of re-endothelialization and ISR in uncoated and coated groups were assessed by SEM and histomorphometric analysis of the implants. As shown in Fig. 9a, severe intimal hyperplasia was found on the surfaces of the uncoated 316 L SS stents, and no cells consistent with an endothelial morphology were observed in the uncoated groups of $316 \mathrm{~L}$ SS stents harvested at 1 or 3 months. In contrast, the coated 316 L SS stents were all completely covered by an intact endothelial monolayer, indicating the enhanced re-endothelialization properties of the $\mathrm{Cu}^{\mathrm{II}}$-Dopa/SeCA coating. Furthermore, hematoxylin eosin (HE) staining on the cross-sections of the arteries together with the vascular stents was performed to quantitatively evaluate intimal hyperplasia and ISR. As clearly seen in Fig. 9b, the uncoated 316L SS stents induced significant intimal hyperplasia and ISR, whereas the coated 316 L SS stents impressively inhibited intimal 

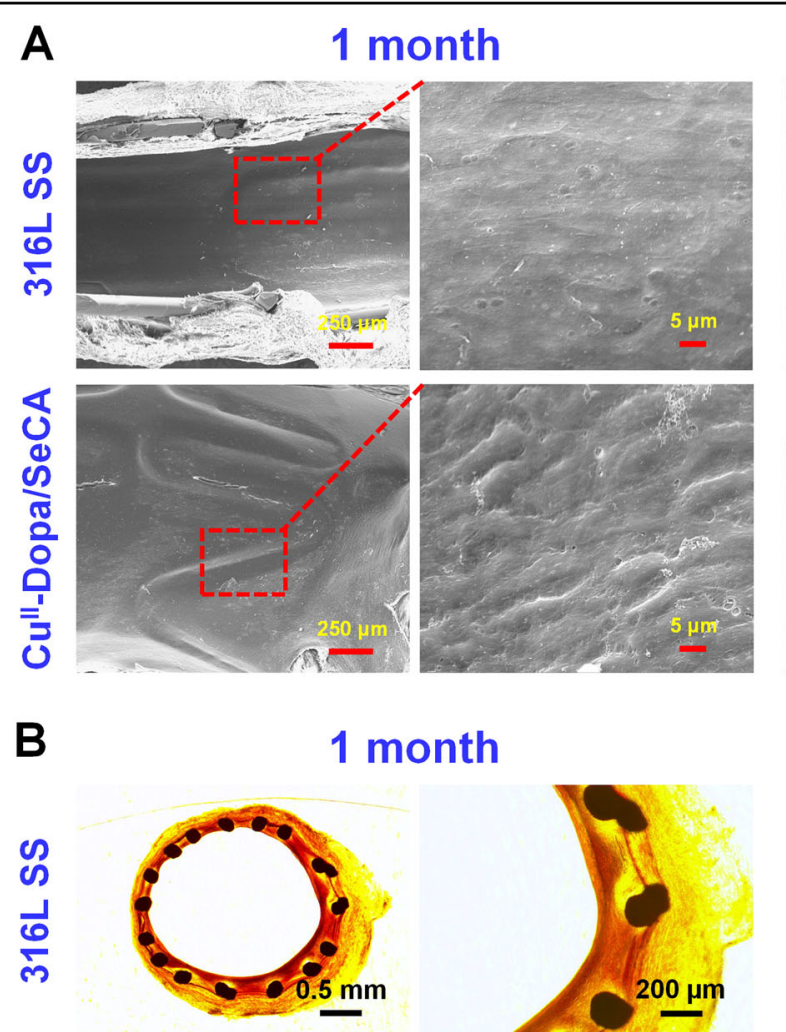

\section{month}
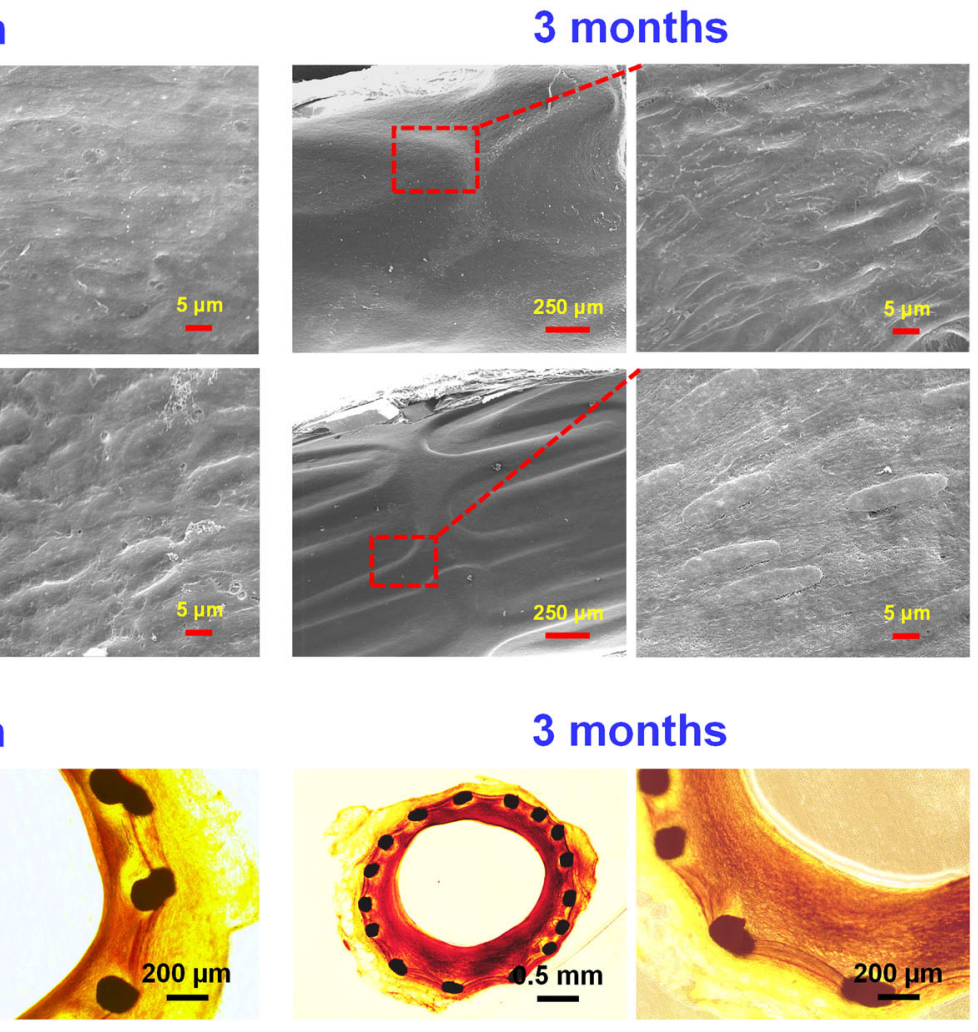

\section{3 months}
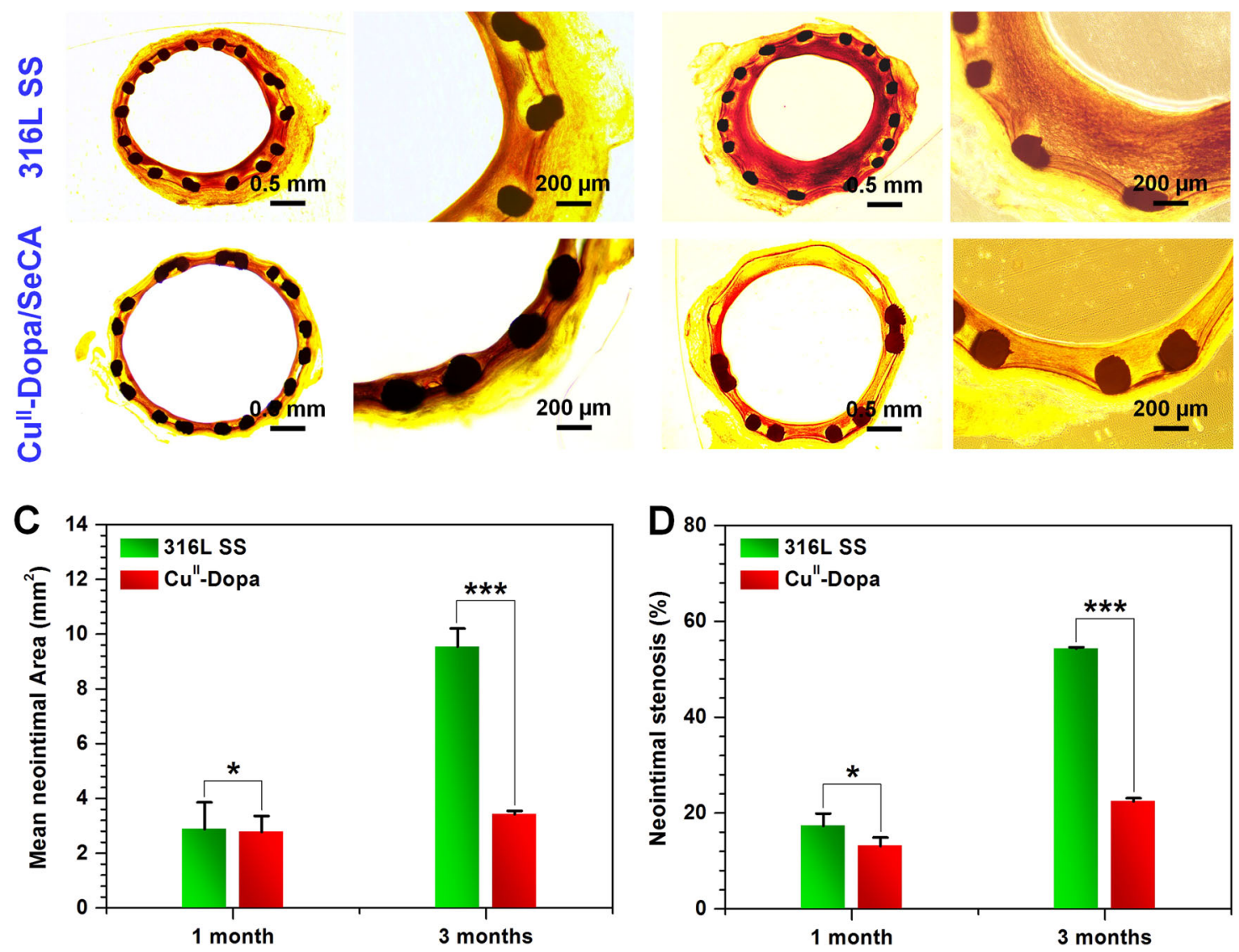

Fig. 9 Cardiovascular stent modified by Cu"-Dopa/SeCA coating for improved performance. a Re-endothelialization of Cu"-Dopa/SeCA-COated and control $316 \mathrm{~L} \mathrm{SS}$ stents after implantation for 1 and 3 months observed by SEM. b The effect of the bare $316 \mathrm{~L} \mathrm{SS}$ and Cu"-Dopa/SeCA-Coated cardiovascular stents on ISR assessed by histomorphometric analysis. c Mean neointimal area and (d) neointimal stenosis analysis indicated significantly reduced ISR. Data are presented as the mean \pm SD of stent implantation experiments and analyzed using one-way ANOVA, ${ }^{*} p<0.05$, ${ }^{* * *} p<0.001$ 
hyperplasia and ISR. Quantitative results from 3 months confirmed that the coated 316 L SS stents decreased the mean neointimal area (Fig. 9c) and neointimal stenosis (Fig. 9d), relative to the uncoated 316 L SS stents by three and two-fold, respectively. Obviously, the developed material-independent synergetic coordination and catecholamine surface chemistry not only opens a new window for efficiently generating therapeutic NO, but also provides an effective strategy to address the clinical issues of cardiovascular stent-associated restenosis and LST.

Continuous release of NO by the endothelium plays a very important physiological role throughout vasculature development ${ }^{6-10}$. The damage to the native endothelium (e.g., caused by atherosclerosis or stent expansion) results in the loss of endothelium functions, causing decreased NO synthesis. Extra supplementation of NO provided by an implanted vascular stent may be a feasible way to enhance the endothelium functions. Although NO shows unique advantages in the treatment of CVDs, excessive NO provided by exogenous sources might be harmful to cells and tissue by causing a greater degree of interactions with superoxide to form peroxynitrites ${ }^{35}$, while an insufficient dose of NO is unlikely to meet the need of the therapy. Therefore, a safe and rational dosing of NO from exogenous sources is crucial for the success of vascular stents. Currently, NO-releasing and NO-generating materials, which are two types of materials that can locally release $\mathrm{NO}$, have been explored for engineering the surface of blood-contacting devices (e.g., tubing, vascular grafts, and stents). For NO-releasing materials, a great challenge limiting their commercialization is the short half-lives of most $\mathrm{NO}$ donors and the uncertainty regarding the amount of $\mathrm{NO}$ generated (burst release of $\mathrm{NO}$ in the initial several days after implantation and insufficient dose of $\mathrm{NO}$ after implantation for 1-2 weeks) for in vivo applications ${ }^{36-39}$. In contrast, our reported NOgenerating coating of $\mathrm{Cu}^{\mathrm{II}}$-Dopa/SeCA demonstrated a relatively long-term, continuous, controllable, and ondemand release of NO. The in vitro NO release showed that the $\mathrm{Cu}^{\mathrm{II}}$-Dopa/SeCA coating could retain $44 \%$ of the catalytic capacity of a native $\mathrm{Cu}^{\mathrm{II}}$-Dopa/SeCA coating (Figure S3), corresponding to an NO-release rate of $2.11 \pm$ $0.54 \times 10^{-10} \mathrm{~mol} \times \mathrm{cm}^{-2} \times \mathrm{min}^{-1}$. Our in vitro biological evaluations demonstrated that the $\mathrm{Cu}^{\mathrm{II}}-\mathrm{Dopa} / \mathrm{SeCA}$ coating prepared using a feed concentration of $\mathrm{CuCl}_{2} \cdot 2 \mathrm{H}_{2} \mathrm{O}$ of $3.125 \mu \mathrm{g} / \mathrm{mL}$ with a release rate of $2.12 \pm 0.13 \times 10^{-10}$ $\mathrm{mol} \times \mathrm{cm}^{-2} \times \mathrm{min}^{-1}$ (Fig. 4) could effectively inhibit platelet adhesion/activation and SMC proliferation. Additionally, our previous work also revealed that an NOgenerating coating subjected to continuous incubation in PBS containing an NO donor for one month retained an approximately $1.8 \times 10^{-10} \mathrm{~mol} \times \mathrm{cm}^{-2} \times \mathrm{min}^{-1}$ release rate of NO. The NO dosing still showed good physiological function for inhibiting platelet activation and SMC proliferation, while enhancing EC proliferation. This implies that the optimized $\mathrm{Cu}^{\mathrm{II}}$-Dopa/SeCA coating in this work could also retain its functions in long-term in vivo applications. As expected, our in vivo stent implantation demonstrated impressively improved anti-thrombogenicity, anti-restenosis, and endothelialization.

\section{Conclusion}

In conclusion, we have developed material-independent coordination and catecholamine synergetic surface chemistry for efficient NO-generating coatings with a metal-catecholamine framework. The metalcatecholamine framework was formed using adhesive 3,4-dihydroxy-L-phenylalanine and $\mathrm{Cu}^{\mathrm{II}}$ ions based on a mussel-inspired molecule/ion coassembly process and equipped with glutathione peroxidase-like activity using organoselenium selenocystamine. The unique metalcatecholamine framework imparts NO-generating coatings with desirable $\mathrm{NO}$ catalysis properties, e.g., longterm, stable, and adjustable range of $\mathrm{NO}$ production rates. The resulting desirable $\mathrm{NO}$ generation endows the NOgenerating coatings with excellent antithrombogenic properties and selective abilities to inhibit HUASMC proliferation and enhance HUVEC adhesion, proliferation, and migration in vitro. These unique features help vascular stents significantly suppress restenosis and promote re-endothelialization in vivo. Therefore, such an efficient NO-generating coating with a coppercatecholamine framework provides a facile, safe, and effective means for addressing the major clinical complications of vascular stents.

\section{Acknowledgements \\ This work was supported by the National Natural Science Foundation of China (Project Key Program 81330031, 31570957, and 81501596), the Distinguished Young Scholars of Sichuan Province (Project 2016JQ0027), and the Fundamental Research Funds for the Central Universities (Project 2682015YXZT07).}

Conflict of Interest

The authors declare no conflict of interest.

Publisher's note

Springer Nature remains neutral with regard to jurisdictional claims in published maps and institutional affiliations.

Supplementary information is available for this paper at https://doi.org/ 10.1038/s41427-018-0052-3.

Received: 8 February 2018 Revised: 24 April 2018 Accepted: 25 April 2018. Published online: 6 June 2018

\section{References}

1. McAloon, C. J. et al. The changing face of cardiovascular disease 2000-2012: An analysis of the world health organisation global health estimates data International journal of cardiology. Int. J. Cardiol. 224, 256-264 (2016).

2. Garg, S. \& Serruys, P. W. Coronary stents: current status. J. Am. Coll. Cardiol. 56, 543-S78 (2010). 
3. Popma, J. J. et al. Quantitative assessment of angiographic restenosis after sirolimus-eluting stent implantation in native coronary arteries. Circulation $\mathbf{1 1 0}$ 3773-3780 (2004)

4. Shah, V. M., Mintz, G. S., Apple, S. \& Weissman, N. J. Background incidence of late malapposition after bare-metal stent implantation. Circulation 106, 1753-1755 (2002)

5. Muller-Hulsbeck, S. et al. Vessel wall damage caused by cerebral protection devices: ex vivo evaluation in porcine carotid arteries. Radiology 235, 454-460 (2005).

6. Mel, A., Murad, F. \& Seifalian, A. M. Nitric oxide: a guardian for vascular grafts. Chem. Rew. 111, 5742-5767 (2011)

7. Elnaggar, M. A. et al. Nitric oxide releasing coronary stent: a new approach using layer-by-layer coating and liposomal encapsulation. Small 12 6012-6023 (2016)

8. Major, T. C. et al. The attenuation of platelet and monocyte activation in a rabbit model of extracorporeal circulation by a nitric oxide releasing polymer. Biomaterials 31, 2736-2745 (2010).

9. Napoli, C. et al. Nitric oxide and atherosclerosis: an update. Nitric Oxide 15, 265-279 (2006)

10. Yang, Z. L. et al. Nitric oxide producing coating mimicking endothelium function for multifunctional vascular stents. Biomaterials 63, 80-92 (2015).

11. Yang, J., Welby, J. L. \& Meyerhoff, M. E. Generic nitric oxide (NO) generating surface by immobilizing organoselenium species via layer-by-layer assembly. Langmuir 24, 10265-10272 (2008).

12. Hwang, S., Cha, W. \& Meyerhoff, M. Polymethacrylates with a covalently linked cuii-cyclen complex for the in situ generation of nitric oxide from nitrosothiols in blood. Angew. Chem., Int. Ed. 45, 2745-2748 (2006).

13. Yang, Y. et al. Development of nitric oxide catalytic coatings by conjugating 3,3-disulfodipropionic acid and 3,3-diselenodipropionic acid for improving hemocompatibility. Biointerphases 10,04A303 (2015).

14. Liu, K. \& Meyerhoff, M. E. Preparation and characterization of an improved Cu2 + -cyclen polyurethane material that catalyzes generation of nitric oxide from S-nitrosothiols. J. Mater. Chem. A. 22, 18784-18787 (2012).

15. Waite, J. H., Housley, T. J. \& Tanzer, M. L. Peptide repeats in a mussel glue protein: theme and variations. Biochemistry 24, 5010-5014 (1985).

16. Harrington, M. J., Masic, A., Holten-Andersen, N., Waite, J. H. \& Fratzl, J. P. Ironclad fibers: a metal-based biological strategy for hard flexible coatings. Science 328, 216-220 (2010).

17. Filippidi, E. et al. Toughening elastomers using mussel-inspired iron-catechol complexes. Science 358, 502-505 (2017).

18. Maier, G. P., Rapp, M., Waite, J. H., Israelachvili, J. N. \& Butler, A. Adaptive synergy between catechol and lysine promotes wet adhesion by surface salt displacement. Science 349, 628-632 (2015).

19. Lee, H., Dellatore, S. M., Miller, W. M. \& Messersmith, P. B. Mussel-inspired surface chemistry for multifunctional coatings. Science 318, 426-430 (2007).

20. Ding, $Y$. et al. Insights into the aggregation/deposition and structure of a polydopamine film. Langmuir 30, 12258-12269 (2014).

21. Yang, Z. L. et al. Direct thrombin inhibitor-bivalirudin functionalized plasma polymerized allylamine coating for improved biocompatibility of vascular devices. Biomaterials 33, 7959-7971 (2012).
22. Ju, K. Y., Lee, Y., Lee, S., Park, S. B. \& Lee, J. K. Bioinspired polymerization of dopamine to generate melanin-like nanoparticles having an excellent freeradical-scavenging property. Biomacromolecules 12, 625-632 (2011).

23. Carpenter, A. W. \& Schoenfisch, M. H. Nitric oxide release: Part II. Therapeutic applications. Chem. Soc. Rev. 41, 3742-3752 (2012).

24. Major, T. C. et al. The hemocompatibility of a nitric oxide generating polymer that catalyzes S-nitrosothiol decomposition in an extracorporeal circulation model. Biomaterials 32, 5957-5969 (2011).

25. Naghavi, N., de Mel, A., Alavijeh, O. S., Cousins, B. G. \& Seifalian, A. M Nitric oxide donors for cardiovascular implant applications. Small 9, 22-35 (2013).

26. Wang, Z. H. et al. Enzyme-functionalized vascular grafts catalyze in-situ release of nitric oxide from exogenous NO prodrug. J. Control Release 210, 179-188 (2015).

27. Zhao, Q. et al. Polysaccharide-based biomaterials with on-demand nitric oxide releasing property regulated by enzyme catalysis. Biomaterials $\mathbf{3 4}, 8450-8458$ (2013).

28. Yao, X. P. et al. Nitric oxide releasing hydrogel enhances the therapeutic efficacy of mesenchymal stem cells for myocardial infarction. Biomaterials $\mathbf{6 0}$, 130-140 (2015).

29. Ignarro, L. J. Influence of structure on N-NO bond cleavage of aliphatic Nnitrosamines. Angew. Chem., Int. Ed. 38, 1882-1892 (1999).

30. Hall, C. N. \& Garthwaite, J. What is the real physiological NO concentration in vivo. Nitric Oxide 21, 92-103 (2009).

31. Ceylan, H., Tekinay, A. B. \& Guler, M. O. Selective adhesion and growth of vascular endothelial cells on bioactive peptide nanofiber functionalized stainless steel surface. Biomaterials 32, 8797-8805 (2011).

32. Wei, Y. et al. Surface engineering of cardiovascular stent with endothelial cell selectivity for in vivo re-endothelialisation. Biomaterials 34, 2588-2599 (2013).

33. Yang, Y. et al. Mussel-inspired one-step adherent coating rich in amine groups for covalent immobilization of heparin: hemocompatibility, growth behaviors of vascular cells, and tissue response. Acs. Appl. Mater. Inter. 6, 14608-14620 (2014).

34. Yang, Z. L. et al. Gallic acid tailoring surface functionalities of plasmapolymerized allylamine-coated 316L SS to selectively direct vascular endothelial and smooth muscle cell fate for enhanced endothelialization. Acs. Appl. Mater. Inter. 6, 2647-2656 (2014).

35. Vaughn, M. W., Kuo, L. \& Liao, J. C. Effective diffusion distance of nitric oxide in the microcirculation. Am. J. Physiol. 274, H1705-H1714 (1998).

36. Balbatun, A., Louka, F. R. \& Malinski, T. Dynamics of nitric oxide release in the cardiovascular system. Acta Biochim. Pol. 50, 61-68 (2003).

37. Lin, C. E. et al. Combination of paclitaxel and nitric oxide as a novel treatment for the reduction of restenosis. J. Med. Chem. 47, 2276-2282 (2004).

38. Buergler, J. M. et al. Use of nitric-oxide-eluting polymer-coated coronary stents for prevention of restenosis in pigs. Coron. Artery Dis. 11, 351-357 (2000).

39. Yoon, J. H. et al. Local delivery of nitric oxide from an eluting stent to inhibit neointimal thickening in a porcine coronary injury model. Yonsei. Med. J. 43, 242-251 (2002) 